\title{
Las influencias en el elitismo en Gonzalo Fernández de la Mora
}

\author{
Influences in the elitism \\ of Gonzalo Fernández de la Mora
}

\author{
CARLOS GOÑI APESTEGUÍA \\ Universidad de Navarra
}

Recibido: 20/02/2013 Aceptado: 12/04/2013

\begin{abstract}
RESUMEN
El pensamiento de Fernández ha sido superficialmente analizado, en la mayoría de los casos, prestando atención exclusivamente a su El crepúsculo de las ideologías. Su concepto de ideología puede ser estudiado desde diversos puntos de vista. Un profundo sustento de este concepto es el elitismo del autor español. Las ideologías aparecen como construcciones estratégicas utilizadas por las elites para ganarse a las masa o para justificar sus intereses. Esta concepción está profundamente influenciada por algunos de los más conocidos teóricos del elitismo. En este artículo se analiza las raíces intelectuales del marco elitista en el que entendía las ideologías.
\end{abstract}

PALABRAS CLAVE

IDEOLOGÍAS, ELITES, MASAS, CLASE DIRIGENTE, MERITOCRACIA

\begin{abstract}
Gonzalo Fernández de la Mora's thought has been superficially analized, in most cases, paying attention only to his famous El crepúsculo de las ideologías. His concept of ideology can be studied from several points of view. A profound support of this concept is the elistism of the spanish author. Ideologies appeared as the strategic construction which elites use to gain masses or to justify their interest. This conception is profoundly influenced by some of the best known elitism theorist. In this paper it is analized the intelectual roots of the elitist framework in which he understand ideologies.
\end{abstract}

(C) Contrastes. Revista Internacional de Filosofia, vol. XIX-N² (2014), pp. 301-318. ISSN: 1136-4076

Departamento de Filosofía, Universidad de Málaga, Facultad de Filosofía y Letras Campus de Teatinos, E-29071 Málaga (España) 


\author{
KEY WORDS \\ IDEOLOGIES, ELITES, MASSES, RULING CLASS, MERITOCRACY
}

\title{
I. INTRODUCCIÓN
}

El CONOCIMIENTO DEL PENSAMIENTo de Gonzalo Fernández de la Mora (19242002) apenas suele rebasar el límite de la mención a su más conocida obra: $E l$ crepúsculo de las ideologías. Probablemente su destacado papel en la cultura y los ambiente políticos a partir de los años cincuenta, su designación ministerial en 1970 y su posterior papel como fundador de Alianza Popular elevaron hasta tal punto su condición de actor político que han acabado por arrojar tinieblas sobre su obra intelectual.

Un aspecto central de la obra más conocida del autor español es, sin duda, la definición de ideología. La que manejó el autor español fue calificada de confusionaria y de arrojar poca luz a la discusión acerca de las ideologías. ${ }^{1}$ Su esclarecimiento no sólo sirve para entender más profundamente la tesis crepuscular sino que, además, dibuja algunas de las líneas más importantes del pensamiento de este autor.

En El crepúsculo de las ideologías Fernández de la Mora define la ideología como una «[...] filosofía política simplificada y vulgarizada» $\mathrm{y}$ «versión popular y pragmática de un sistema de ideas». ${ }^{2}$ En 1963 aparece ya esta definición en los textos de Fernández de la Mora que se incluirán posteriormente como epígrafes en esta obra. ${ }^{3}$ La variación, o adición, más significativa respecto a esta definición original es la inclusión del dramatismo o patetismo como elemento consustancial a las ideologías. ${ }^{4}$ Otros como Raymond Aron, Freund o Pareto ya habían llamado ya la atención sobre el dramatismo de la ideología. Pero en la

1 Sabino Alonso Fueyo que consideraba que la definición que daba Fernández de la Mora de la ideología «no proyecta mucha luz sobre el tema», además de entender que las sociedades contemporáneas siguen siendo ideológicas. S. Alonso Fueyo 1965. Fernández de la Mora reconoce en una carta del 24-III-1965 que las ulteriores discrepancias se basan en esa falta de sintonía en cuanto a la definición: «Muchas gracias por tu muy amistoso artículo sobre mi libro. Creo que nuestra discrepancia fundamental arranca de una diferente acepción del vocablo básico: ideología».

2 G. Fernández de la Mora 1986a, p. 59.

3 «Una ideología es algo así como una filosofía simplificada, vulgarizada y directamente aplicada a la vida colectiva». Definición que aparece en: G. Fernández de la Mora 1963. Este artículo será incorporado como parte del texto de ECI.

4 G. Fernández de la Mora 1965; G. Fernández de la Mora 1974; G. Fernández de la Mora 1976, p. 134; G. Fernández de la Mora 1984c, pp. 268-269; G. Fernández de la Mora 1989a, p. 83; G. Fernández de la Mora 1989b, p. 135; G. Fernández de la Mora 1991b, p. 164; G. Fernández de la Mora 1992, p. 4. 
perspectiva del pensamiento de Fernández de la Mora la racionalización como fenómeno estructurador y fuerza motriz de la historia comporta una marginación de los elementos emotivos, un elemento de disolución de las ideologías.

Si la dimensión patética es fundamental para entender la concepción de ideología en el autor español, no lo es menos, el carácter masivo de las ideologías, es decir, el hecho de que son productos para las grandes masas. Fernández de la Mora consideraba que este aspecto era uno de los más débiles de las ideologías. Y lo era porque su comprensión elitista de la sociedad le llevaba a pensar en las ideologías como meros instrumentos para la dominación de las masas. Esta concepción no se daba en el vacío sino que formaba parte de un interesante background filosófico del autor. La explicitación del itinerario intelectual de las influencias que determinan el elitismo del autor español ayudan a entender su repudio de las ideologías.

\section{El carácter trascendental del elitismo: Gaetano Mosca}

Gaetano Mosca fue una de las principales influencias en el pensamiento de Fernández de la Mora en torno al elitismo. El autor italiano llegó a la convicción de que en toda sociedad existen unas minorías que ostentan todos los puestos de poder, «la clase dirigente», frente a una mayoría desunida que se corresponde con la masa. El dualismo clase gobernante/clase gobernada es un trascendental de la organización política que puede aplicarse a toda comunidad. La clase gobernante siempre es menos numerosa que la gobernada y tiende a monopolizar todas las funciones políticas, mientras la segunda está sujeta al poder de la gobernante reduciéndose su labor a proporcionar los medios materiales de subsistencia del organismo político. ${ }^{5}$

Para Mosca, señala Sánchez Cámara, hay dos tipos de razones para entender la superioridad de la clase dirigente sobre la dirigida. ${ }^{6}$ En primer lugar, hay un motivo funcional que se basa en el carácter organizado de la minoría. La fuerza de la minoría organizada es irresistible para una mayoría, la masa, en la que no hay organización. El individuo inserto en una masa se encuentra, en realidad, enfrentado a una colectividad de mayor porte, la elite, ya que él no forma parte de un cuerpo unido, organizado. ${ }^{7}$ Esto no implica que en la clase gobernante haya una unidad indisoluble. De hecho, está compuesta por facciones o grupos en pugna por el poder por lo que la unidad no es total.

5 G. Mosca 1953a, p. 78.

6 I. Sánchez Cámara 1986, pp. 110-111.

7 «El estado de desorganización de la mayoría deja a cada uno de sus miembros particulares impotente ante el poderío organizado de la minoría. Precisamente porque es una minoría, un grupo más bien pequeño, puede lograr lo que la mayoría no puede: comprensión y una acción concertada». I. Zeitling 1970, pp. 224-225. 
Además, al margen de las diferencias entre facciones, Mosca señala que en la clase gobernante hay una división entre quienes directamente ostentan y ejercen directamente el poder de manera efectiva y quienes colaboran para que estos lo ejerzan.

El motivo funcional-organizativo no es el único que diferencia a ambas clases. Mosca observa que los individuos de la clase dirigente poseen una superioridad material, racional o, incluso, moral.

Pero además de la gran ventaja derivada de la organización, las minorías gobernantes son constituidas de manera que los individuos que las componen se distinguen de la masa de los gobernados por cierta cualidad, que les proporcionan cierta superioridad material e intelectual o incluso moral, y son los herederos de esa cualidad que poseen: en otras palabras, deben tener algún requisito real o aparente que sea fuertemente apreciado y que se imponga en la sociedad en la que viven. ${ }^{8}$

Al margen de la superioridad funcional de la minoría sobre la mayoría hay, por tanto, una superioridad cualitativa. ${ }^{9}$ Pero ¿qué nota es la realmente distintiva entre la clase gobernada y la gobernante? Mosca aborda abiertamente el tema de quiénes son los mejores retomando la teoría platónica del gobierno de los mejores. La respuesta aportada por Mosca es ligeramente confusa ya que por un lado señala que la diferencia no es propiamente moral sino que se basa en la capacidad de hacerse con el espíritu de su tiempo. ${ }^{10}$ Pero, por otra parte, afirma que la cualidad distintiva del dirigente es la «bondad». Esta bondad se cifra en la superación de sus intereses personales a favor de los intereses de la comunidad toda. Sin embargo, esta aristocracia rara vez toma parte en la dirección del Estado, aunque influye en su acción. ${ }^{11}$

8 La traducción es mía. Para consultar el texto original: «Però, oltre al vantaggio grandissimo che viene dall'organizzazione, le minoranze governante ordinariamente sono constituite in maniera che gl'individui che le compongono, si distinguono dalla massa dei governati per certa qualitá, che dànno loro una certa superiorità materiale ed intellettuale od anche morale, oppure sono gli eredi di coloro che queste qualitá possevedano: essi in altre parole devono avere qualche requisito, vero od aparente, che è fortemente aprezzato e molto si fa valere nella società nella quale vivono». G. Mosca 1953a, p. 83.

9 Diferencia que puede ser meramente apariencial en clara conexión con el pensamiento de Maquiavelo. Para la interpretación de Mosca en relación con el pensamiento maquiaveliano: J. Burnham 1953, pp. 87-121.

10 «Inteso in questo senso l'aggetivo può essere sempre, in tempi normali, applicato alle classi dirigente, perchè il fatto che sono tali dimostra che in una data epoca, ed in un dato paese, esse contengono gli elementi più atti a governare; ciò che non sempre significa che siano gli elementi più elevati intellecttualmente e sopratutto moralmente». G. Mosca 1953b, p. 177.

11 Ibid, p. 241. 
La dificultad surgida de esta aparente contradicción entre el carácter moral o no de la elite se disipa si atendemos a la doble dimensión que sobre este problema traza el autor italiano. Por un lado, cuando afirma que la diferencia no es propiamente moral está haciendo una fenomenología del poder, está describiendo como se comporta el poder efectivamente. Mientras que, por otro lado, cuando afirma la necesaria superioridad moral, el altruismo, de la clase dirigente se sitúa en un plano normativo, en el plano del deber ser. ${ }^{12}$

Todavía cabe aludir a otro concepto de la teoría de Mosca que extendería la influencia sobre Fernández de la Mora más allá de la consideración elitista de la sociedad. Esta noción es la de «fórmula política» que bien podría asimilarse con el concepto de «ideología». ${ }^{13}$ La fórmula política es el principio de soberanía o la justificación que tiene la clase gobernante para continuar en el poder o para legitimar su posición. ${ }^{14} \mathrm{El}$ autor italiano señala que la clase gobernante precisa para mantenerse en el poder de una construcción jurídico-moral que la legitime. Se trata de un elemento de dudosa racionalidad pero tampoco irá tan lejos como para indicar que son mera retórica engañosa, se trata, más bien, de elementos necesarios para que el gobernado no lo sea meramente por la fuerza coactiva. ${ }^{15}$

Las «fórmulas políticas» son ficciones o mitos necesarios para cimentar la unidad y la organización de un pueblo. Mosca entiende que ninguna sociedad puede mantenerse unida al margen de éstas construcciones. La identificación de estas construcciones con las ideologías no requiere demasiados artificios conceptuales. ${ }^{16}$ Aquí vuelve a conectar la teoría de la elite de Mosca con la filosofía maquiavélica que está en el fondo de toda consideración ideológica.

12 Asimismo no sería difícil retrotraer esta diferenciación de elites a dos conceptos como son el de la autoridad y el poder.

13 Cfr. J. H. Meisel 1962, p. 55.

14 «Questa base giuridica e morale, sulla quale in ogni società poggia il potere della classe politica, è quella che in altro lavoro abbiamo chiamato e che d'ora in poi chiameremo formola politica, e che i filosofi del diritto appellano generalmente principio di sovranità». G. Mosca. 1953a, p 109.

15 «Ciò però non vuol dire che le varie formole politiche siano volgari ciarlatanerie inventate appositamente per scroccare l'obbedienza delle masse, e sbaglierebbe di molto colui che in questo modo le considerasse. La verità è dunque che esse correspondo ad un vero bisogno della natura sociale dell'uomo; e questo bisogno, così universalmente sentito, di governare e sentirse governato non sulla sola base della forza materiale ed intellettuale, ma anche su quella di un principio morale, ha indiscutibilmente la sua pratica e reale importanza». Ibid, p. 110.

16 Según Meisel su doctrina de las «fórmulas políticas» lo sitúa más cerca de Marx de lo que Mosca suponía. MEISEL, James Hans (1962): 57. Sánchez Cámara recoge esta opinión señalando: «Se trata de una noción que guarda íntima relación con la ideología en sentido marxista. La fórmula política cumple una función legitimadora del poder». I. Sánchez Cámara 1986, p. 113. 
Lo cierto es que la teoría elitista del autor italiano parece postular las «fórmulas políticas», léase ideologías, como necesarias para convencer, aunque con falsedades, a las masas de gobernados. Sin embargo, la postulación de esta necesidad o de su fuerza funcional no elimina su carácter de ilusión colectiva. Esta es, sin duda, una diferencia capital respecto a Fernández de la Mora. En su aproximación fenomenológica al poder, el autor español coincide en la presencia de estas construcciones pero no considera que sean necesarias $\mathrm{y}$, de hecho, viene a llamar la atención sobre el inicio de su declive, lo que significa la posibilidad de una historia sin ellas.

\section{La CirCulación de las elites en Vilfredo Pareto}

La doctrina elitista de Mosca, a su vez, recibirá un importante impulso teórico con su dinamización por parte de Vilfredo Pareto a quien Fernández de la Mora denominó «el gran formulador del elitismo político». ${ }^{17} \mathrm{El}$ autor español se sentirá especialmente interesado en la teoría elitista de Pareto al entender que ésta tesis da razón de la sucesión política o el cambio social. ${ }^{18}$ Aunque coincidentes en el punto de partida de la tesis, la división elitista de toda sociedad, Pareto alumbra con su teoría de la circulación de las elites un concepto dinámico en la consideración del elitismo. ${ }^{19}$ Junto con Mosca, Pareto ha puesto los fundamentos para la consideración del elitismo moderno. ${ }^{20}$

Desde luego, para Pareto es indudable que la configuración o división entre clase dirigente y clase dirigida es una forma trascendental que se observa allá donde miremos, aunque tenga formas diferentes de organizarse. ${ }^{21}$ En todo lugar, al igual que en la teoría de Mosca, es una oligarquía la que detenta el poder. ${ }^{22}$ Sin embargo, en la teoría paretiana la elite no tiene un contenido exclusivamente político. Como señala Aron, en la obra de Pareto se puede hablar de dos sentidos de «elite». Por un lado, un sentido amplio que engloba a toda elite social mientras que, por otro, hay un sentido exclusivamente gubernamental, o político, de la elite. ${ }^{23}$

17 G. Fernández de la Mora 1984a, p. 326.

18 Lo mismo opina Sánchez Cámara. «La concepción paretiana es fundamentalmente dinámica. Aporta básicamente una teoría sobre el cambio social». I. Sánchez Cámara 1986, p. 119.

19 G. Fernández de la Mora 1977, p. 29.

20 La influencia de Mosca en Pareto se basa en el hecho de pasar de considerar a las elites por notas relativas a la distribución de atributos para pasar a considerarla como una simple oposición omnipresente entre elites gobernantes y masas. Cf. T. B. Bottomore 1964, p. 3.

21 «Il existe partout une classe gouvernante, même là où il y a un desposte; mais les formes sous lequelles elle apparait sont diverses». V. Pareto 1968, \& 2253, p. 1442.

22 Cf. Ibid, \& 2183, p. 1395.

23 R. Aron 2004, p 375. 
En efecto, por un lado, Pareto define a la elite como los mejores individuos en «todas las ramas de la actividad humana». ${ }^{24}$ Es decir, hace de esa clase un concepto extensible a toda dimensión de la vida humana. Es el concepto, más amplio de elite. ${ }^{25}$

Pero, por otro lado, este autor hablará particularmente de la elite gubernamental, «élite gouvernementale», formada por aquellos que juegan un rol directo o indirecto en el gobierno de la sociedad, frente a la elite no-gubernamental, «elite non-gouvernementale». ${ }^{26}$ Ambas están sujetas a la ley que establece la circulación de las elites. ${ }^{27}$

La teoría de la circulación de las elites tiene como punto de partida la caducidad de toda elite. ${ }^{28}$ Las elites no duran para siempre y está comprobado históricamente que tras un cierto tiempo la imperante desaparece y es sustituida por otra. ${ }^{29}$ La historia es un continuo cambio de elites dirigentes que se suceden entre sí en un flujo constante. Esta visión paretiana contribuye a explicar el cambio histórico, de ahí que su visión de la historia no sea estática sino dinámica. A la aristocracia imperante le sucederá otra pero en cualquier caso habrá una elite que se situará al frente de la sociedad.

La circulación de las elites supone el cambio no de los individuos o dinastías sino de los tipos de individuos que conforman la elite..$^{30}$ De hecho, el principio y la sucesión aristocrática supone el peor obstáculo para la libre circulación de la elite. ${ }^{31}$ Para Pareto, la circulación de las elites es necesaria para que la sociedad no caiga, se atrofie y muera, al igual que en los animales se produce la sustitución de unos elementos, por ejemplo las células, por otros. ${ }^{32}$ Ahora

24 La traducción es mía. Cfr. V. Pareto 1968, \& 2027, p. 1296.

25 «Formons donc une classe de ceux qui ont les indices les plus élevés dans la branche où ils déploient leur activité, et donnons à cette classe le nom d'élite. Tout autre nom et même une simple lettre de l'alphabet, seraient également propres au but que nous nous proposons». Ibid, 2013, p. 1297.

26 Cf. Ibid, \& 2033, p. 1297.

27 Cf. Ibid, \& 2041, p. 1299.

28 «Elites themselves do not endure; they are replaced by other elites once they can no longer sustain a strong conviction in their beliefs, because they have lost the energy and drive to do what must be done to retain authority». M. Mclure 2001, p. 57.

29 Cf. V. Pareto 1968, \& 2053, p. 1304.

30 Cf. J. Burnham 1953: p. 213.

31 Así lo señala Burnham exponiendo la doctrina de Pareto. «El más notorio y universal de los obstáculos para lograr la libre circulación de las élites lo constituye el principio aristocrático. Los hijos de los miembros de la élite reciben toda clase de ayuda para ocupar una posición en la élite sin tener en cuenta sus capacidades, e impidiendo, por lo tanto, que otros individuos más capacitados de la «no élite» ocupen esos puestos». Ibid, p. 214.

32 «Il y a là un processus semblable à celui qui s'observe chez l'animal vivant, lequel ne subsiste qu'en en eliminant certain éléments et en les remplaçant par d'autres, qu'il s'assimile. Si 
bien, la composición de las elites estará condicionada en cada momento por el principio de selección por lo que, siguiendo a Burnham, la elite no está compuesta necesariamente por los mejores de cada sociedad sino por aquellos favorecidos por el criterio de selección..$^{33}$

Hay también un elemento en la teoría paretiana que puede ser asimilado, al igual que en Mosca, al concepto de ideología de Fernández de la Mora como son las «derivaciones» paretianas. La doctrina de las derivaciones y los residuos conecta con la teoría de las elites en el punto en el que el establecimiento de derivaciones puede afectar la libre circulación de las elites. ${ }^{34}$

Las derivaciones paretianas son asimiladas a las ideologías precisamente en lo que tienen de revestimiento racional de pulsiones no lógicas. ${ }^{35}$ Las derivaciones, al igual que las ideologías, son «argumentos arbitrarios para justificar sentimientos»». ${ }^{36}$ Las derivaciones en Pareto son una forma de justificar determinadas pulsiones pasionales. Según este autor la mayoría de las acciones humanas son irracionales. ${ }^{37}$ Las derivaciones son las construcciones por las que éstas pulsiones o conductas irracionales, los «residuos», adquieren una apariencia racional. Así las derivaciones acaban por ser formas de legitimar racionalmente las pasiones, esto es, ideologías. ${ }^{38}$

cette circulation est suprimée, l'animal meurt, il est déstruit. Il en est de même pour l'élite sociale et si la destruction peur en être plus lente, elle n'en est pas moins sûre». V. Pareto 1978, p. 11.

33 De la misma opinión es Wright Mills en su crítica al sistema norteamericano: «Those who sit in the seats of the high and the mighty are selected and formed by the jeans of power, the sources of wealth, the mechanics of celebrity, which prevail in their society». C. W. Mills 1976, p. 361.

34 «Las derivaciones, también, tienen cierta influencia en el equilibrio social, aunque Pareto, como ya hemos visto, cree que se trata de un factor de menos importancia y que sólo ejerce una influencia indirecta en comparación con los factores importantes. Esas creecncias no-lógicas, mitos y fórmulas ofrecen gran interés sobre todo cuando se los considera como expresiones de los residuos o de los intereses, y por su poder indirecto de reforzar los residuos o alterar el patrón de la circulación de las elites». J. Burnham 1953, p. 210.

35 «A esta clase de concepciones pseudocientíficas las denominó Pareto derivaciones. Su análisis constituye una de las aportaciones más válidas del genial pensador. Pareto clasifica las derivaciones en simples afirmaciones de anécdotas, de ficciones, o de emociones; en alegaciones del principio de autoridad; en elevación de los sentimientos colectivos a principios; $y$ en sofismas lógicos. Su inexorable análisis sólo excepcionalmente afecta a las ideologías políticas a pesar de que en su inmensa mayoría son arquetipos de derivación». G. Fernández de la Mora 1991a, pp. 262-263.

36 G. Fernández de la Mora 1991b, p. 164.

37 Cf. V. Pareto 1968, 153, p. 68.

38 Así lo interpreta Sánchez Cámara: «La teoría de las derivaciones constituye la versión paretiana de la teoría de la ideología como legitimación de la acción social». I. Sánchez Cámara 1986, p. 120. 
Por tanto, al análisis fenomenológico que establece el carácter trascendental de la elite se suma, nuevamente, una doctrina de la ideología como forma de justificación social. Además la dinámica de las elites, la doctrina de la circulación, hace que las ideologías, las derivaciones, en Pareto adquieran una connotación agonal, es decir, de lucha en el contexto de unas elites en pugna por la preeminencia social. Esta belicosidad se convierte en Fernández de la Mora en uno de los principales argumentos en contra de la funcionalidad de las ideologías. La relación polémica entre ellas llega a convertirlas en hipertensivas lo que elimina su positiva función de vacuna frente a la abulia social.

\section{LA LEY DE HIERRo DE LA Oligarquía De Robert Michels}

Otro de los autores que marcó el pensamiento elitista del que Fernández de la Mora es deudor es, precisamente, un autor fuertemente influido por el pensamiento de Mosca y de Pareto: Robert Michels. El autor alemán quiso demostrar que en todas las organizaciones, incluso las supuestamente animadas por el ideal democrático, hay una minoría dominante. Michels desarrolló al efecto las tesis establecidas por sus dos predecesores haciendo un análisis especial de los partidos políticos y realizando la primera incursión de este estilo en la estasiología o doctrina de los partidos. El alemán establecerá lo que se ha denominado la «ley de hierro de la oligarquía» de la que se hizo eco la doctrina de Fernández de la Mora.

Para Michels el principal factor que impone la vigencia de una oligarquía consiste en que la organización de toda asociación humana presupone necesariamente la jerarquización. ${ }^{39}$ Este análisis refleja además una concepción totalmente negativa de la masa. Por un lado, la masa es notablemente manipulable merced a su tamaño. Así, las masas son más intransigentes y más susceptibles al entusiasmo exagerado desapareciendo en ellas el individuo y, con él, la personalidad y el sentido de la responsabilidad. Las masas son, además, totalmente incapaces de tomar resoluciones, es decir, de decidir y gobernar. ${ }^{40}$ La crítica de Michels a las masas se debe a su incapacidad técnica.

En la teoría de Michels la masa aparece como un ser mostrenco caracterizada por una clara incapacidad para la decisión y la innovación, es decir, para

39 «La organización implica la tendencia a la oligarquía. En toda organización, ya sea de partido político, de gremio profesional, u otra asociación de ese tipo, se manifiesta la tendencia aristocrática con toda claridad. El mecanismo de la organización, al conferirle solidez de estructura, induce algunos cambios importantes en la masa organizada, e invierte completamente la posición respectiva de los conductores y los conducidos. Como consecuencia de la organización, todos los partidos o gremios profesionales llegan a dividirse en una minoría de directivos y una mayoría de dirigidos». R. Michels 1984, pp. 77-78.

40 «Las masas soberanas son incapaces de adoptar las resoluciones más necesarias». Ibid, p. 71. 
el liderazgo ${ }^{41}$ Incluso se muestran poco interesadas por la dirección de sus propios asuntos. Las masas abdican de los asuntos públicos, que se les presentan como asuntos indiferentes y cuando irrumpen en la vida pública suele ser por la acción de un líder con voluntad de remover a quien ostenta el poder o por un movimiento fácilmente sofocable fruto de un desacuerdo profundo con la voluntad de los líderes. ${ }^{42}$ La masa requiere del liderazgo de un individuo que tome las decisiones que ella no puede tomar. Cuando la masa se ve sin líder se angustia y huye o se inhibe completamente. ${ }^{43}$ Debido a este anhelo de liderazgo, las masas tratan a los líderes como héroes y su sentimiento hacia ellos es de gratitud que es otro de los factores de la superioridad de los líderes sobre las masas. ${ }^{44}$ Las masas tienden a adular a sus líderes, lo que contribuye no sólo a perpetuar sino a fortalecer la tendencia oligárquica. ${ }^{45}$

La oligarquización de la sociedad, y de toda organización, tiene su origen en dos hechos fundamentales. Por un lado, la complejidad de la organización hace inviable cualquier asociación que no se estructure oligárquicamente. La oligarquización es un fenómeno al servicio de la viabilidad y funcionalidad de las organizaciones. Por otro lado, las masas se retraen de la decisión y dirección, es decir, se anulan como elemento directivo, fenómeno éste que reclama la aparición de una elite dirigente. Pero ¿cuál es el factor que establece la diferencia esencial entre las masa y las oligarquías? Para Michels el factor predominante de superioridad de las elites respecto de las masas es, por encima de la superioridad económica o histórica, la superioridad intelectual. ${ }^{46}$ Es el conocimiento especializado de los dirigentes lo que abre una brecha insalvable con respecto a la masa incapaz de organizarse y, como se ha señalado, anhelante de liderazgo. ${ }^{47}$

Fernández de la Mora entiende que la teoría de Michels relega al hombre medio a la condición de incompetente político, pues no tiene en cuenta la

41 «La necesidad de guía que experimenta la masa, y su incapacidad para actuar cuando le falta una iniciativa de afuera y desde arriba, impone, sin embargo, una pesada carga a los jefes». Ibid, p. 101.

42 Cf. Ibid, p. 194.

43 Michels apela a un ejemplo bélico afirmando que cuando la masa se encuentra en el campo de batalla y se queda sin líder huye despavorida hasta que aparecen nuevos capitanes. Cf. Ibid, p. 100.

44 Cf. Ibid, p. 103.

45 «Las masas experimentan una necesidad profunda de prosternarse, no solo ante grandes ideales, sino también ante individuos que personifican a sus ojos aquellos ideales». Ibid, p. 108.

46 Cf. Ibid, p. 120.

47 «Esta competencia especial, este conocimiento de expertos, que el líder adquiere en cuestiones inaccesibles, o casi inaccesibles, para la masa, le da seguridad de su posición, lo cual desafía principios esenciales de la democracia». Ibid, p.123. 
capacidad de elevación cultural de las masas. ${ }^{48}$ La situación de las masas no es, para el autor español, un estado permanente sino que puede cambiar gracias a la acción educadora. De hecho, la tesis crepuscular tiene como punto de partida una elevación del nivel de las masas que desechan los productos ideológicos gracias a la mayor densidad cultural de la población. Por tanto, se puede decir que, aunque partiendo de una concepción similar respecto de las masas, Fernández de la Mora no acepta la concepción estática de Michels. El autor español considera que es plausible la adquisición de conciencia y voluntad política por parte de las masas.

El lugar del concepto de ideología en el pensamiento de Michels es residual. La razón fundamental es, quizá, la caricatura que hace del concepto de masa, un concepto en el que la muchedumbre no sólo permanecerá eternamente en la minoría de edad política sino que no precisa de una justificación por parte de una oligarquía a la que idolatra y trata con sentimiento de gratitud. Sin embargo, al tratar la ideología bonapartista, Michels, muestra cómo actúa la ideología. En esta exposición tiene un interés especial la «ilusión» o el carácter ilusorio de toda ideología. ${ }^{49}$ Sin embargo, esta alusión es vaga y ocupa, como se señalaba, un lugar muy secundario en su obra, lo que refuerza la teoría de que la posición de las masas es tan débil en su pensamiento que las elites no precisan de un elemento legitimador. La única legitimación necesaria es el desvalimiento de las masas. De hecho, las discrepancias en torno al carácter de la masa y la consecuente ausencia de una doctrina de la ideología permiten hacer pensar que Fernández de la Mora vio en la obra de Michels simplemente la constatación del carácter oligárquico de los partidos políticos, con la consiguiente desmitificación de la democracia que conlleva. ${ }^{50}$

48 «El hombre medio, como integrante de la masa, ¿es por naturaleza un eterno incompetente ante la problemática política? Esta tesis de Michels no puede aceptarse en su tajante formulación, porque la ignorancia no es un mal social incurable. Gracias a una intensa educación nacional, apoyada en la creciente capacidad técnica del Estado, en los nuevos métodos pedagógicos y en los medios de comunicación de masas, se han obtenido resultados tan espectaculares como la erradicación del analfabetismo y la masificación de la enseñanza universitaria. Que las cotas alcanzadas sean todavía insatisfactorias no permite afirmar una incapacidad incurable, sino que, por el contrario, obliga a prever una culturización general progresiva. El diagnóstico de Michels se fundaba en la ignorancia popular y en las técnicas de enseñanza a principios de siglo. No es lícito afirmar hoy la incapacidad invencible del hombremasa para pronunciarse con cierto conocimiento de causa sobre algunas cuestiones que afectan a la comunidad»G. Fernández de la Mora 1977, pp. 51-52.

49 Cf. R. Michels 1984, p. 17 y ss.

50 «Desde la perspectiva de la sociología empírica, se probó que las elites políticas no son nunca el producto de la voluntad de las masas, sino que las minorías se seleccionan a sí mismas por autoafirmación y concurrencia». G. Fernández de la Mora 1984b, p. 469. Fernández de la Mora atribuía esta idea a Mosca, Pareto y Michels, fundamentalmente. Sin embargo, hubo 


\section{El elitismo de José Ortega y Gasset}

Si hay un autor que destaca como influencia principal en el elitismo de Fernández de la Mora ese es José Ortega y Gasset. Fernández de la Mora consideraba la sociología, donde fundamentalmente abordaba el elitismo, como «la disciplina predilecta de Ortega». ${ }^{51}$

Ortega es uno de los grandes representantes de la teoría aristocrática de la sociedad en España. Para el filósofo español la división en dos estratos cualitativos no es sólo un hecho social sino la misma condición de posibilidad de la sociedad. Tanto las naciones ${ }^{52}$ como cualquier otro género de sociedad se presentan organizadas en torno a la distinción entre elites y masas. Esta estructuración es la razón de ser de la sociedad, sin esta estructura la sociedad esta próxima a su desaparición o, directamente, no existe. ${ }^{53}$

La condición aristocrática de toda sociedad es un factum. No se trata de que el autor español sea un defensor de la aristocracia como modelo social, es decir, no le da un lustre normativo, más bien se trata de la constatación de un hecho esencial. La esencia misma de la sociedad le impone el aristocratismo, de ahí que sea éste un hecho radical. ${ }^{54}$ La pregunta por si una una sociedad debe o no ser aristocrática no es más que una pseudopregunta. ${ }^{55}$ Sin embargo, esta separación, en ocasiones, puede diluirse por una degeneración de las elites o un desvío de las masas. Ortega habla de dos tipos de época en relación a este proceso de disolución o fortalecimiento de la sustancia social, es decir, de la división aristocrática. Las épocas Kali son aquellas en las que las aristocracias

un autor que utilizó este prisma para analizar la democracia parlamentaria: Carl Schmitt. Es obvio que para el autor alemán el parlamentarismo fracasa en la medida en que deja de ser un mecanismo para la selección de elites. Cfr. Schmitt, Carl 1990, pp. 6-12.

51 G. Fernández de la Mora 1979, p. 221.

52 J. Ortega y Gasset 2006b, p. 96.

53 «El hecho primario social no es la mera reunión de unos cuantos hombres, sino la articulación que en ese ayuntamiento se produce inmediatamente. El hecho primario social es la organización en dirigidos y directores de un montón humano. Esto supone en unos cierta capacidad para dirigir; en otros, cierta facilidad íntima para dejarse dirigir. En suma: donde no hay una minoría que actúa sobre una masa colectiva, y una masa que sabe aceptar el influjo de una minoría, no hay sociedad, o se está muy cerca de que no la haya». Ibid, p. 98.

54 «Es radical, porque yo no he dicho nunca que la sociedad humana deba ser aristocrática, sino mucho más que eso. He dicho, y sigo creyendo, cada día con más enérgica convicción, que la sociedad humana es aristocrática siempre, quiera o no, por su esencia misma, hasta el punto de que es sociedad en la medida en que sea aristocrática, y deja de serlo en la medida en que se desaristocratice». J. Ortega y Gasset. 2007, p. 88.

55 «Resulta completamente ocioso discutir si una sociedad debe ser o no debe ser constituida con la intervención de una aristocracia. La cuestión está resuelta desde el primer día de la historia humana: una sociedad sin aristocracia, sin minoría egregia, no es una sociedad». J. Ortega y Gasset 2006b, pp. 107-108. 
se degradan con lo que la separación se diluye y la sociedad se ve amenazada. Por el otro lado, están las épocas Kitra en las que se da la formación de una aristocracia. ${ }^{56}$ Para Ortega el fenómeno de la rebelión de las masas por él descrita es un ejemplo de época Kali.

La disolución de la división, el trastorno de sus límites, equivale al caos y la desintegración social. Es preciso detenerse brevemente para descubrir en qué consiste exactamente esta división. ${ }^{57}$

Ortega señala que la razón de ser de esta distinción no es económica ya que en todo grupo hay masa y aristocracia. ${ }^{58}$ Las razones por las que existen estas dos clases es mucho más complejo y tiene una raigambre netamente antropológica. Superficialmente la diferencia entre ambos grupos se basa en la cualificación. Minoría son aquellos individuos «especialmente cualificados» mientras que las masas son los no cualificados. ${ }^{59}$ Sin embargo, la cualificación no se refiere simplemente a un asunto de capacidades o competencias. La diferencia entre la minoría selecta y la masa va más allá y tiene una raigambre antropológico-moral. La diferencia fundamental es una autoexigencia ética, una disciplina. Gracias a esta disciplina y a la autoimposición de unas normas, la minoría se autoselecciona. ${ }^{60}$ La vida del hombre selecto, egregio, es por eso un continuo ejercicio de autobligación en vista a un mayor nivel de exigencia y perfección. Su esfuerzo es caracterizado por Ortega en términos agonales o deportivos: con él logra separarse, seleccionarse respecto a los demás. Lo propio de la minoría es privación, esfuerzo y obligación y de ahí que su vida sea entrenamiento o ascesis. ${ }^{61}$

56 Cf. Ibid, pp. 101-104.

57 No en vano Sánchez Cámara señala que la división entre minorías y masas es el punto central de la sociología de Ortega.

58 Cfr. J. Ortega y Gasset 2006b, p. 109; J. Ortega y Gasset 2007, p. 84.

59 J. Ortega y Gasset 2007, p. 82.

60 «El hombre que se impone a sí propio una disciplina más dura y unas exigencias mayores que las habituales en el contorno, se selecciona a sí mismo, se sitúa aparte y fuera de la gran masa indisciplinada donde los individuos viven sin tensión ni rigor, cómodamente en los otros y todos a la deriva, vil botín de las resacas». J. Ortega y Gasset 2004, p. 666.

61 «A las minorías selectas no las elige nadie. Por la sencilla razón de que la pertenencia a ellas no es premio o una sinecura que se concede a un individuo, sino todo lo contrario, implica tan sólo una carga mayor y más graves compromisos. El selecto se selecciona a sí mismo al exigirse más que a los demás. Significa, pues, un privilegio de dolor y de esfuerzo. Selecto es todo el que desde un nivel de perfección y de exigencias aspira a una altitud mayor de exigencias y perfecciones. Es un hombre para quien la vida es entrenamiento, palabra que, como he hecho notar en recientes conferencias, traduce exactamente lo que en griego se decía ascetismo. (El ascetismo, áskesis, es el régimen de vida que seguía el atleta, lleno de ejercicios y privaciones constantes para mantenerse en forma. Este vocablo tan puramente deportivo es acaparado luego por los cenobitas y monjes y pasa a significar la dieta del hombre religioso, resuelto a mantenerse 
De este tipo de vida elegido por el individuo egregio se deriva su singularidad. El individuo que adopta semejante forma de existencia, que abraza este imperativo moral de vivir esforzadamente, se separa de la mayoría, se individualiza separándose por «razones especiales». Sólo una vez que el individuo se ha separado de la masa se une a otros que conforman la minoría, mientras que en la masa se produce la pura indiferenciación. El individuo se siente en ella «como todo el mundo» sin sentir ninguna angustia por ello sino que, al contrario, se encuentra satisfecho con esta condición. ${ }^{62}$

Esta última precisión nos lleva a afirmar que la doctrina de la minoría selecta y la masa no está estrictamente relacionada con el concepto de vocación en Ortega, aunque como es obvio guarda relaciones con él. La vocación es algo dado en el hombre, algo recibido, ante lo cual sólo caben dos opciones: la fidelidad o la traición. En estos límites se dibuja una vida auténtica o inauténtica. La vocación dibuja un ámbito de obligaciones inherentes al yo. Se trata de una obligación dada. La autoexigencia en que consiste la selección minoritaria forma parte de una obligación autoimpuesta por el sujeto que no necesariamente tiene porque referir a su vocación. Ortega, como se ha señalado, afirma que las minorías se eligen a sí mismas, se seleccionan imponiéndose un imperativo ético, el de vivir esforzadamente. En cambio, en el caso de la vocación el hombre es elegido, es decir, recibe una vocación que puede ser una vocación vulgar o una vocación excelente, pero la catadura de la vocación no define al sujeto como minoría o como masa.

La emulación, la ejemplaridad, es la relación que existe, ha de existir, entre las minorías y las masas. La dominación de las elites sobre las masas no precisa de una cortina falsaria, por lo que las ideologías no son, en opinión de Ortega, un elemento necesario. La masa percibe al individuo egregio como tal y éste le sirve para la elevación de su propia condición. El aristócrata no necesita justificarse, ni tratar de ganarse el apoyo de los grandes números. Es decir, no hay en Ortega una teoría de la ideología y esta ausencia se da por dos motivos. En primer lugar, porque el aristócrata orteguiano no busca ser reconocido. Su decisión de ser minoría es ética y no responde a ninguna intención maquiavélica o una libido dominandi. De ahí que Ortega recalque que la distinción entre masa y minoría no es sólo, ni principalmente, política. Desde luego la política es una de las esferas en las que se refleja pero se trata de una relación que se extiende a todos los ámbitos de la socialidad. ${ }^{63}$

en estado de gracia, esto es, en forma, para lograr el premio a la beatitud)». J. Ortega y Gasset 2006b, p. 201.

$62 C f$. J. Ortega y Gasset 2007, p. 83.

63 «Cuando la subversión moral de la masa contra la minoría mejor llega a la política, ha recorrido ya todo el cuerpo social». J. Ortega y Gasset 2006b, p 102. 
En segundo lugar, no hay una doctrina de la ideología porque la relación de admiración, de emulación voluntaria, es el estado normal de la sociedad. ${ }^{64}$ En sus dos obras principales acerca del aristocratismo, España invertebrada y $L a$ rebelión de las masas, establece dos patologías de subversión de esta relación. En el primero, la sobreabundancia de pueblo y la ausencia de minoría, es decir, el desequilibrio de la relación es una anomalía ${ }^{65}$ Asimismo, la aristofobia se presenta como una enfermedad. ${ }^{66}$ En la segunda obra, la rebelión de las masas aparece como una subversión de la relación natural entre ambos grupos. Es un fenómeno de decadencia y por tanto una «desocialización», por cuanto, ataca la esencia misma de la sociedad. El fenómeno de rebeldía de las masas es la «más grave crisis que a pueblos, naciones, culturas cabe padecer»» ${ }^{67}$

Para Fernández de la Mora la teoría aristocrática de la sociedad de Ortega es uno de los puntos centrales de su pensamiento. ${ }^{68}$ Fernández de la Mora califica como «aristocratismo sublimado». La visión aristocrática de la sociedad lo inunda todo en Ortega y su visión de la historia es claramente elitista. ${ }^{69}$ Esa sublimación la conectará, en su interpretación de Ortega, con el presunto antidemocratismo del autor madrileño concluyendo que hay en éste una sentencia a favor del autoritarismo y de las instancias decisorias frente a las deliberativas. $^{70}$ A la luz de la concepción aristocrática de la sociedad las declaraciones democráticas de Ortega sólo serían «declaraciones marginales». Lo cierto, es que el pensamiento de Ortega es estructuralmente aristocrático, elitista.

Fernández de la Mora retoma el carácter vital de las elites para la sociedad y su carácter trascendental. De hecho, la crisis de las ideologías se podría tranquilamente interpretar como una época Kitra, es decir, una época de formación de elites que supone la salida de la época Kali de la preponderancia de las ideologías. El crepúsculo de las ideologías describe a este respecto el fenómeno opuesto a La rebelión de las masas.

$64 C f$. I. Sánchez Cámara 1986, p. 73.

65 Cf. J. Ortega y Gasset 2006b, pp. 131-133.

$66 C f$. Ibid, pp. 115. También califica este fenómeno de odio o insurrección de las masas respecto a la minoría como una «perversión de los afectos». Ibid, p. 136.

67 «Hay un hecho que, para bien o pera mal, es el más importante en la vida pública europea de la hora presente. Este hecho es el advenimiento de las masas al pleno poderío social. Como las masas, por definición, no deben ni pueden dirigir su propia existencia, y menos regentar la sociedad, quiere decirse que Europa sufre ahora la más grave crisis que a pueblos, naciones, culturas cabe padecer». J. Ortega y Gasset 2007, p. 79.

68 «El extracto vertebral de Ortega es el aristocratismo, la permanente invitación a lo superior». G. Fernández de la Mora 1983a.

69 «Como he mostrado en otras ocasiones, su interpretación de la Historia era aristocrática; su idea de la sociedad minoritaria; y su concepción del Estado, técnica y elitista». G. Fernández de la Mora 1983b, p. 212.

70 G. Fernández de la Mora 1979, pp. 170-174. 


\section{CONCLUSIÓN}

A través de estas influencias Fernández de la Mora eleva a la condición de axioma de su pensamiento sociológico el carácter jerárquico de toda agrupación humana. Quien quiera ver en la obra de Fernández de la Mora una propugnación de la idoneidad del elitismo, un carácter normativo en su análisis de las elites, o un intento por forzar una «dimisión colectiva de la sociedad» ${ }^{71}$ ignora el hecho de que para Fernández de la Morael elitismo es un dato de lo real. El elitismo es un fenómeno trascendental a toda organización social que no por negado deja de ser menos constitutivo. El carácter elitista tiene dos corolarios políticos.

En primer lugar, la comprensión de todo sistema político como un medio para la cooptación de las elites. Toda forma política es un método, un instrumento, para la elección de las elites dirigentes que tienden a agruparse de manera más o menos férrea en búsqueda de la consecución del poder. En la medida en que este método sea más acertado en la renovación de las elites y, ante todo, permita el acceso de los más aptos será un régimen más adecuado. Ninguna forma de gobierno puede aspirar a ser la concreción de un supuesto régimen ideal. ${ }^{72}$ Asimismo, este realismo implica una desmitificación de las formas de gobierno, tesis que, como declara el propio autor había tomado de Javier Conde. ${ }^{73}$

El segundo corolario, siguiendo la misma línea, es la condena de la ideología como método para la justificación de las pretensiones de poder de las elites. La ideología aparece como un falso medio de legitimación de la voluntad de poder de una elite. Esta justificación tiene una clara impronta de ardid maquiavélico que no sólo resulta falsario sino que mantiene a las masas en una continua minoría de edad política. Para Fernández de la Mora, es preciso partir del hecho de que toda sociedad es jerárquica y que las ideologías no son más que intentos de dominación revestidos de carácter científico o, en no pocos casos, moral.

La tesis sobre el fin de las ideologías esta penetrada de esta concepción elitista. El fenómeno implica una ley sociológica en la que la elevación del nivel cultural de las masas conlleva la reducción de la vitalidad y funcionalidad de las ideologías. ${ }^{74}$ La crisis de las ideologías implica un cambio en la valoración

71 J. M. Ortí Bordás 1967, p. 9.

72 El desarrollo más claro y profundo de esta tesis se puede encontrar en: G. Fernández de la Mora 1972.

73 Cf. G. Fernández de la Mora 1995, p. 54.

74 «Hace veinte años describí en este libro un fenómeno supranacional que hasta entonces apenas había sido entrevisto, y formulé una ley sociológica: cuanto mayores son la racionalización y el desarrollo de un grupo humano menor es la vigencia de las recetas simplistas de los demagogos, o ideologías, y más intenso es el recurso a las ideas científicas de los expertos acerca de lo que debe hacerse». G. Fernández de la Mora 1986a, p. 33. 
judicativa de las masas a la hora de elevar a la dirección a una elite.$^{75} \mathrm{La}$ crisis de las ideologías significa la revalorización de la meritocracia, es decir, la correcta valoración y elección de las elites de acuerdo a sus capacidades y no a su pericia retórica.

\section{REFERENCIAS BIBLIOGRÁFICAS}

ALONSO FUEYO, Sabino (1965): «Polémica en torno a las ideologías» en Arriba de 21-III-1965.

ARON, Raymond (2004): Las etapas del pensamiento sociológico, Tecnos, Madrid. BOTTOMORE, Thomas Burton (1964): Elites and Society, Watts, Londres, 1964.

BURNHAM, James (1953): Los maquiavelistas, Emecé, Buenos Aires.

GIMÉNEZ CABALLERO, Ernesto (1986). «Poesía y razón en nuestro XVIII» en Razón Española, 20, p. 349-350.

FERNÁNDEZ DE LA MORA, Gonzalo (1963): «Distensión y crisis de las ideologías» en $A B C$ de 31-XII-1963.

—, (1965): «Ideologías e ideales» en $A B C$ de 29-V-1965.

-, (1972): Del Estado ideal al Estado de razón, Real Academia de las Ciencias Morales y Políticas, Madrid.

-, (1974): «La convergencia de las ideologías» en $A B C$ de 13-VII-1974.

—, (1976): El Estado de Obras, Doncel, Madrid.

-, (1977): La partitocracia, Instituto de Estudios Políticos, Madrid.

—, (1979): Ortega y el 98, Rialp, Madrid.

-, (1980): «El aristocratismo de Ortega» en $A B C$ de 16-VIII-1980

—, (1983a): «Ortega, un siglo» en $A B C$ de 28-I-1983

—, (1983b): «Ortega entre la II República y la II Restauración» en Razón Española, 2, p. 205-212.

—, (1984a): «Mussolini y d'Ors» en Razón Española, 3, p. 1-3.

—, , (1984b): «Schmitt y la democracia» en Razón Española, ,4, p, 452-469.

—, (1984c): «Sobre lo irracional» en Razón Española, 7, p. 261-272.

-, (1986a): El crepúsculo de las ideologías, Espasa-Calpe, Madrid.

-, (1986b): «Razonalismo y racionalismo» en Razón Española, 20, p. 257-259.

—, (1989a): «También se desideologiza la URSS» en Razón Española, 33, p. 81-83.

—, (1989b): «El intelectual y el político» en Razón Española, 37, p. 133-160.

—, (1991a) «Las ideologías, sin futuro» en Razón Española, número 47.

-, (1991b): «Contradicciones de la partitocracia» en Razón Española, 49, p. 153-204.

-, (1992): «Razón y prejuicio» en Razón Española, 51, p. 3-5.

-, (1995): Río arriba, Planeta, Barcelona.

75 «La retórica política ha sufrido una mutilación profunda: han pasado de moda las arengas electrizantes y la hinchada grandilocuencia. En su lugar se han instalado las ruedas de prensa y los informes rigurosos. El político se ha despojado de su atrezzo altisonante y enfático, para tratar de convertirse en un gerente modesto y eficaz». Ibid, p. 84. 
MCLURE, Michael (2001): Pareto, Economics and Society, Routledge, LondresNueva York.

MEISEL, James Hans (1962): The myth of the ruling class. Gaetano Mosca and the elite, Ann Arbor, Michigan.

MICHELS, Robert (1984): Los partidos políticos. Un estudio sociológico de las tendencias oligárquicas de la democracia moderna, Amorrortu, Buenos Aires.

MILLS, C. Wright (1976) The power elite, Oxford University Press, Nueva York.

MOSCA, Gaetano (1953a): Elementi di Scienzia Politica, G. Laterza, Bari, T. I.

—, (1953b): Elementi di Scienzia Politica, G. Laterza, Bari, T. II.

ORTEGA Y GASSET, José (2004): «El deber de la nueva generación argentina» en Obras Completas, T. III, Taurus, Madrid.

—, (2006a): «Cosmopolitismo»» en Obras Completas, T. V, Taurus, Madrid.

—, (2006b): España invertebrada, Austral, Madrid.

—, (2007): La rebelión de las masas, Austral, Madrid.

ORTÍ BORDÁS, José Miguel (1967): La nueva derecha española, Inmansa, Madrid.

PARETO, Vilfredo (1968): «Traité de sociologie général» en Oeuvres Complètes,

Tomo XII, Droz, Ginebra.

—, (1978) «Les systémes socialistes» en Oeuvres Complètes, Tomo V, Droz, Ginebra.

SÁNCHEZ CÁMARA, Ignacio (1986): La teoría de la minoría selecta en el pensamiento de Ortega y Gasset, Tecnos, Madrid.

SCHMITT, Carl (1990): Sobre el parlamentarismo, Tecnos, Madrid.

ZEITLING, Irving (1970): Ideología y teoría sociológica, Amorrortu, Buenos Aires.

Carlos Goñ Apesteguía es colaborador investigador en el Instituto Cultura y Sociedad de la Universidad de Navarra.

Publicaciones recientes

Teoría de la razón política. El pensamiento político de Gonzalo Fernández de la Mora, Centro de Estudios Políticos y Constitucionales, 2013.

El crepúsculo de las idelogías, Edición, notas y estudio introductorio, Olms, 2013.

Dirección electrónica: goni85@hotmail.com 